\title{
Effects of Patients' Expectation in Dermatology: Evidence from Experimental and Clinical Placebo Studies and Implications for Dermatologic Practice and Research
}

\author{
Wiebke Sondermann ${ }^{\mathrm{a}}$ Finja Reinboldt-Jockenhöfer ${ }^{\mathrm{a}} \quad$ Joachim Dissemond $^{\mathrm{a}}$ \\ Oliver Pfaar ${ }^{b}$ Ulrike Bingel ${ }^{c}$ Manfred Schedlowski ${ }^{d, e}$ \\ ${ }^{a}$ Department of Dermatology, Venereology, and Allergology, University Hospital Essen, University of Duisburg- \\ Essen, Essen, Germany; ${ }^{b}$ Section of Rhinology and Allergy, Department of Otorhinolaryngology, Head and Neck \\ Surgery, University Hospital Marburg, Philipps University Marburg, Marburg, Germany; 'Department of Neurology, \\ University Hospital Essen, University of Duisburg-Essen, Essen, Germany; ${ }^{d}$ Institute of Medical Psychology and \\ Behavioral Immunobiology, University Hospital Essen, University of Duisburg-Essen, Essen, Germany; ${ }^{\text {eDepartment }}$ \\ of Clinical Neuroscience, Osher Center for Integrative Medicine, Karolinska Institutet, Stockholm, Sweden
}

\section{Keywords}

Dermatologic diseases · Expectation · Learned immune

function $\cdot$ Nocebo $\cdot$ Placebo

\begin{abstract}
Patients' expectations towards the benefit of a treatment are key determinants of placebo responses and can affect the development and course of medical conditions and the efficacy and tolerability of active medical treatment. The mechanisms mediating these placebo and nocebo effects have been best described in the field of experimental pain and placebo analgesia. However, also in dermatology experimental and clinical studies demonstrate that various skin diseases such as inflammatory dermatoses and allergic reactions can be modulated by patients' expectations. Dermatologists should consider the important modulatory role of patients' expectations on the efficacy and tolerability of specific treatments and the key role of verbal information, patients' prior treatment experiences (associative learning), and the quality and quantity of doctor-patient communication in shaping treatment expectation. As a consequence, techniques aiming at maximizing patients' expectation effects should be implemented into daily clinical routine. By
\end{abstract}

contrast, in clinical studies expectation effects should be maximally controlled and harmonized to improve the "assay sensitivity" to detect new compounds. Further translational studies, also in dermatoses that have not been investigated yet, are needed to better characterize the mechanisms underlying patients' expectation and to gain further insights into potential clinical implications of these effects in dermatologic conditions. Therefore, in this review, we provide a brief overview on the concept of expectation effects on treatment outcome in general, summarize what is already known about this topic for dermatologic diseases, and finally present the relevance of this topic in clinical dermatology.

(c) 2021 S. Karger AG, Basel

\section{Introduction}

A large body of evidence from the last two decades indicates that patients' expectations towards the benefits of a certain therapy significantly influence the development and course of disease symptoms and the efficacy as well as tolerability of active medical treatment [1-7]. The pivotal role of expectation is best illustrated in experimental or clinical studies involving placebo (inactive) treatment karger@karger.com

(C) 2021 S. Karger AG, Basel

www.karger.com/drm

Karger!
Wiebke Sondermann

Department of Dermatology, Venereology, and Allergology

University Hospital Essen, University of Duisburg-Essen

Hufelandstr. 55, DE-45122 Essen (Germany)

wiebke.sondermann@uk-essen.de 
groups or conditions. Following a placebo treatment, symptom improvements cannot be explained by specific properties of a drug. Instead, they are substantially determined by, e.g., natural variations of the underlying disease and by patients' expectations regarding the benefit of the drug treatment as induced by the informed consent procedure or other information provided prior to the study. Meta-analyses of randomized controlled trials (RCTs) in various clinical conditions have revealed that a large portion of symptom improvement can be attributed to positive expectation effects, which are referred to as placebo effects $[8,9]$. Psychological and physiological changes in response to treatment expectation have been observed in almost every physiological system and in distinct clinical conditions $[5,10,11]$. However, in the field of dermatology, patients' expectation effects have only relatively recently received attention based on the steadily growing evidence from experimental and clinical studies, suggesting that skin diseases and allergic reactions can be modulated by interventions other than conventional drug therapy [11-15].

The aim of our review is to provide a current overview of the empirical evidence for the effects of patients' expectation in the field of dermatology and to present the relevant implications for dermatologic practice and research, thereby addressing key challenges and open questions for basic experimental research and clinical trials.

\section{Psychological Factors Shaping Treatment Expectation}

As a general definition, the placebo response, i.e., the overall treatment effects observed in the placebo arm of RCTs, is composed of various factors, such as the natural history of a disease or fluctuation of symptoms, response biases, effects of co-interventions, or statistical phenomena, such as regression to the mean $[5,10,16,17]$. In addition, experimental and clinical data indicate that the observed unspecific treatment or placebo effects are, at least in part, steered by patients' expectations towards a benefit of a treatment $[9,16-20]$. These data demonstrate that patients' positive treatment expectations can reduce disease symptoms and enhance treatment efficacy with positive effects on health outcome. In contrast, negative treatment expectation can induce a nocebo effect associated with increased symptomatology, diminished treatment effect, and less beneficial health outcome $[17,21]$. Patients' expectations are mediated through verbal information, e.g., from health care professionals, or via per- sonal prior treatment experiences. In addition, observing treatment benefits in others affects treatment expectation as well as characteristics of the therapeutic context or intervention itself [17, 22-24].

In health care systems, direct verbal communication with doctors or nurses as well as written information in form of medication leaflets have been shown to affect patients' treatment expectation, treatment efficacy and tolerability, and finally treatment outcome [18, 19, 25-28]. On the basis of associative learning procedures, prior treatment experiences affect patients' expectations. For example, if pain reduction is experimentally induced in volunteers by behavioral conditioning procedures (unbeknownst to the participants), the effect of this prior experience is more effective in reducing pain than just verbal information [29]. In addition, based on associative learning procedures, repeated exposure to pharmacological agents can induce a response that mimics the effects of the drug itself $[17,30]$. This phenomenon is also referred to as "pharmacological conditioning" and has been demonstrated in learned immunopharmacological placebo responses in healthy volunteers [31-33] and immunosuppressed renal transplant patients $[34,35]$. Such an effect was also demonstrated in psoriasis patients under topical glucocorticoid therapy, who were successfully treated with interspersed placebo in the sense of a placebo-controlled dose reduction [12].

Observing positive or negative treatment effects in others can also affect patients' treatment expectation and treatment outcome. These social observation effects have been demonstrated in particular in experimental and clinical studies of pain [17, 36-38]. Finally, contextual factors such as the features of the medical setting, the clinical environment, the invasiveness of the intervention, as well as the appearance of the health care provider are also able to shape patients' expectation and treatment outcome $[39,40]$. For example, more invasive interventions such as acupuncture, surgery, injections, or infusions seemed to induce a more pronounced treatment expectation and subsequently a larger health benefit than less invasive oral treatments such as ingestion of a pill [41, 42].

\section{Neurobiological Mechanisms Underlying the Effects of Treatment Expectations}

Experimental studies involving placebo and nocebo conditions have begun to unravel the mechanisms that mediate the effects of positive and negative treatment expectation on neurobiological and peripheral-physiologi- 
cal levels. These mechanisms are best characterized in the field of experimental pain and placebo analgesia [17, 43]. Neuroimaging studies demonstrate that placebo analgesia involves descending pain modulatory pathways such as the dorsolateral prefrontal cortex, the anterior cingulate cortex, and the periaqueductal gray [44]. Data from a meta-analysis indicate that placebo treatments have minimal effects on responses in the neurologic pain signature, a central nervous system marker that tracks the intensity of nociceptive pain, suggesting a multivariate brain pattern tracking nociceptive pain [45]. The causal role of prefrontal cortices in placebo analgesia is supported by studies showing that transient lesioning of the dorsolateral prefrontal cortex [46] or degeneration of frontal lobes in Alzheimer disease is associated with a decrease in or a complete loss of expectation-induced analgesia [47]. Other regions such as the anterior insula and the striatum also seem to play a role $[48,49]$, and there is reason to believe that various neural systems may underly placebo analgesia depending on how it is induced. While studies inducing conscious expectations, e.g., by verbal instruction, have been associated with activity in the dorsolateral prefrontal cortex, other neural circuits involved in placeboby-proxy mechanisms or associative learning may play a role, especially in patients who are unlikely to form their own conscious treatment expectations, such as Alzheimer disease patients or small children [50].

Endogenous opioids, dopaminergic neurotransmission, as well as the endocannabinoid system have been shown to be pivotal for the implementation of placebo analgesia [51-54]. The endogenous cholecystokinin system, a system tightly related to anxiety, seems to significantly modulate nocebo hyperanalgesia [55]. In models of experimental animals simulating learned placebo responses in immune functions in humans, the learned immunosuppressive responses were mediated via the insular cortex and noradrenergic, beta-adrenoceptor-dependent mechanisms, thus identifying the major neurobiological pathway of learned immunosuppressive placebo responses $[35,56]$. However, the involvement of joint and distinct brain mechanisms steering placebo responses across various bodily systems still remains unclear [44].

\section{Interindividual Differences of Susceptibility to Placebo Responses}

Expectation effects on health outcomes vary considerably among individuals in both experimental and clinical scenarios. While some subjects respond well to pla- cebo interventions and thus show pronounced responses (responders), others do not respond at all (nonresponders) $[2,5,10,57,58]$. Especially if it is administered for the first time, not every individual responds to a placebo. Data indicate that placebo analgesia is more robust when preconditioning with analgesic treatments is performed, pointing to a critical role of learning in placebo responsiveness [59]. Identifying biological or psychological predictors for responsiveness to placebo manipulations would be of great value not only for the development of new drugs in placebo-controlled RCTs, but also for routine clinical care $[6,7,15,60]$. Although the prediction of an individual's effect of treatment expectation on health outcome would be important to inform therapeutic decisions in a personalized manner, data on these interindividual differences are rare and controversial $[3,5,58]$.

Psychological factors such as state anxiety, stress, and negative affect as well as neuroendocrine factors associated with these factors can modulate an individual's response to positive and negative treatment expectation in placebo analgesia $[18,61-64]$. Whether and to what extent these findings translate into other physiological systems and end organ functions is currently unclear. Another factor that complicates matters further is that there is evidence that a person who responds to a placebo in one treatment may not respond in another treatment [58]. Data obtained from healthy volunteers suggest that placebo responses may not be dependent on stable individual traits, but rather are more a characteristic of the state circumstances of individuals or a combination of both trait and state $[58,65]$. Taken together, so far no reliable placebo responder profile has been validated $[2,57,58]$. In addition, it is important to note that there seemed to be major differences regarding the role of expectations between healthy volunteers and patients. In healthy volunteers, there is often a strong correlation between expectancy and placebo effects $[66,67]$, whereas in chronic pain patients, conscious expectation does not reliably predict placebo effects $[68,69]$.

Interindividual variation in the responsiveness to placebo manipulations has also been linked to properties of the individual's brain. First evidence from pain research suggests that the structural and functional connectivity of the brain at rest can at least in part predict the influence of expectations on health outcomes in an individual [7076]. In addition, experimental data indicate that genetic factors are also likely to contribute to an individual's response to treatment expectations $[59,60,77]$.

Dermatology 2021;237:857-871 




Fig. 1. Schematic overview of the potential beneficial effects of positive treatment expectations and the main factors influencing expectation effects. Additionally, the figure summarizes various dermatologic conditions in which expectation effects have been shown to have an impact.

\section{Effects of Patients' Treatment Expectation in Dermatologic Symptoms and Disorders}

Evidence for the clinical relevance of treatment expectation in dermatology is increasing steadily. In the next section, we summarize what is already known about this topic for dermatologic symptoms and diseases. Figure 1 sums up various dermatologic conditions in which expectation effects have been shown to have an impact.

\section{Itch}

Itch is an annoying sensory sensation associated with the urge to scratch. It is the cardinal symptom of multiple dermatologic conditions such as atopic dermatitis (AD). Itch is known to be significantly influenced by cognitive and emotional factors [78] and has a high impact on patients' quality of life $[79,80]$. Itch shares many neural pathways with chronic pain, including peripheral and central sensitization of nerve fibers, and both conditions respond similarly to acute stress [81]. Current data indi- cate that verbal information and suggestion play a central role in placebo and nocebo effects on subjective and behavioral parameters in itch $[13,82]$. Suggestions of high and low itch or pain were able to respectively enhance and decrease the self-reported parameters of itch and pain after mechanical and electrical stimulation [83], and a combination of conditioning and verbal suggestion have been shown to be most promising in inducing both positive and negative treatment expectation effects [84]. The impact of verbal suggestion is also evident from so-called "open-label placebo" studies, in which positive expectations are typically induced by describing the "power of the placebo effect" as being established through conditioning and expectations and working through mind-body processes to improve health. By employing these open-label placebo approaches the ethical issues involved in the deceptive prescription of placebos is avoided $[9,85,86]$.

In a proof-of-concept study in healthy volunteers, selfreported itch evoked by histamine iontophoresis was significantly lower in the open-label placebo experimental 
group compared to the control group [87]. In another study by the same group, positive verbal suggestions induced significantly lower expected itch compared to negative suggestions in both open-label and closed-label conditions, indicating the important role of verbal suggestions in optimizing patients' expectations and subsequent treatment effects for itch in clinical practice. However, data were obtained in healthy volunteers, and a direct comparison to the clinical situation of patients must be made with caution [88]. The data confirm the efficacy of the open-label placebo approach in depression, irritable bowel syndrome, or chronic back pain, where the severity of symptoms could be substantially reduced by open-label placebos [85, 89-95].

Evidence for associative learning effects in itch comes from an experimental study in healthy volunteers investigating the efficacy of a behaviorally conditioned antihistaminergic response using an $\mathrm{H}_{1}$ antagonist for histamine-induced itch. Marginally lower itch responses were documented in the combined conditioned groups compared to the controls, indicating a learned antipruritic response, regardless of whether participants were informed about the conditioning procedure [96]. Patients suffering from chronic itch respond with higher levels of perceived itch compared to healthy controls upon observing audiovisual material, such as crawling insects, scratch sounds, and other people scratching $[97,98]$. This phenomenon is referred to as contagious itch and emphasizes the role of observational learning in itch [13]. However, it is important to note that contagion has to be differentiated from the actual treatment context.

Only a few studies have investigated the neurologic pathways and brain activation pattern involved in treatment expectation effects in dermatologic conditions such as itch. Data indicate associations between nocebo responses and activation in brain areas which are responsible for the somatosensory processing of itch or related to the itch-scratch cycle [97-100]. However, caution is needed in interpreting these findings, as only negative expectation (nocebo) effects have been analyzed and half of the studies were investigating contagious itch [82]. In summary, the available data indicate that placebo and nocebo responses in itch can be induced in healthy volunteers and patients by verbal suggestions and associative learning procedures [82]. However, the underlying neuropsychological and neurobiological mechanisms are still not well understood [11] (Fig. 1).

\section{Chronic Spontaneous Urticaria}

Chronic spontaneous urticaria (CSU) is an unpredictable itchy dermatosis with a high impact on patients' quality of life. The disease is associated with a high psychological burden inducing negative feelings such as anxiety, depression, reduced self-esteem, and sleep disturbances [101-103]. In a recent meta-analysis about the placebo effects on itch in clinical trials in patients with $\mathrm{AD}$, psoriasis, and CSU, treatment expectation effects on itch were found to be largest in patients with CSU, indicating a susceptibility of these patients to placebo interventions [104]. In clinical trials assessing new investigational drugs in CSU patients, however, the manifestation of placebo responses has not been of major concern [105, 106].

\section{Psoriasis}

Psoriasis is a chronic inflammatory skin disorder with a strong impact on patients' lives frequently associated with psychiatric diseases, especially depression [107, 108]. Recent data underpin that stress and central nervous changes can contribute to new onset or exacerbation of psoriasis via a dynamic bidirectional cross-talk between the nervous system and cutaneous immune cells. Thus, signals of inflammatory mediators and cytokines also lead to behavioral, metabolic, and cardiovascular responses in the brain [109]. This "brain-skin axis" is a prerequisite for associative learning processes [35]. In patients with mild-to-moderate psoriasis under treatment with topical corticosteroids, the concept of a dose reduction strategy via a "partial reinforcement" treatment strategy could be successfully demonstrated. Full-dose medication was given for a set period of time (acquisition period) followed by a maintenance or evocation period with interspersed placebo treatment. Using this "partial reinforcement" paradigm, drug efficacy could be maintained while the amount of corticosteroid medication required was reduced [12]. As shown by this example, reframing long-term drug intake as a learning process in the sense of a so-called "placebo-controlled dose reduction" opens up a new avenue for maximizing treatment efficacy that could also decrease drug dosages, reduce unwanted side effects, and cause lower treatment costs $[2$, 17, 30, 35] (Fig. 1).

\section{Allergic Reactions}

IgE-mediated allergic reactions include a variety of conditions such as allergic rhinitis/rhinoconjunctivitis, food allergies, allergic asthma, or anaphylaxis. Experimental and clinical evidence suggests that psychological factors and neuroimmunological mechanisms are involved in the modulation of allergic reactions $[110,111]$. Allergic disorders seem to be highly susceptible to pla- 
cebo responses, as documented by placebo response rates of $20-40 \%$ in clinical trials of allergic diseases $[4,15,112-$ 117] (Fig. 1).

Allergic Rhinoconjunctivitis. Data indicate that patients with allergic rhinoconjunctivitis are highly responsive to psychological factors [116-119] and that disease symptoms can be modulated by interventions other than conventional drug therapy $[110,120,121]$. In controlled clinical trials of allergen immunotherapy (AIT) the placebo response was reported to be up to $77 \%$ compared to pretreatment severity of symptoms for both application routes of AIT, sublingual AIT, and subcutaneous AIT [15, $119,122]$. Factors such as patients' expectations and learning mechanisms are hypothesized to be responsible for this high placebo response in AIT $[15,116,123,124]$. In addition, open-label placebos were also shown to improve symptoms in allergic rhinoconjunctivitis [125, 126]. The disease course and outcome in allergic rhinoconjunctivitis are also affected by associative learning paradigms [15]. When a specific taste was paired with a house dust mite allergen challenge during training (acquisition), re-exposure to the taste stimulus induced increased mast cell tryptase levels in nasal lavage fluid in allergic patients [127]. Similarly, seasonal grass allergens were paired with an olfactory cue in hay fever sufferers. Allergic subjects re-exposed to the olfactory cue released significantly higher levels of histamine [128]. In another learning paradigm, patients with house dust mite allergy received a novel-tasting drink (conditioned stimulus) once daily, followed by a standard dose of the $\mathrm{H}_{1}$ receptor antagonist desloratadine, on 5 consecutive days during acquisition and were re-exposed to the conditioned stimulus once. Subjective symptom scores and wheal sizes after skin prick tests were significantly reduced by the learning procedure as well as by verbal instruction (control group). Basophil activation, however, which plays a critical role in the modulation of the allergic response, was significantly suppressed in the conditioned group only [32]. These results were confirmed and extended in a learning paradigm in which allergic reactions were documented by wheal size after skin prick test and symptom scores after nasal provocation at baseline, after the last desloratadine treatment and after the first and fifth reexposure to the conditioned taste stimulus. Both conditioned and sham-conditioned patients showed significantly decreased wheal sizes after the first conditioned stimulus evocation and significantly decreased symptom scores after the first as well as after the fifth evocation compared to the control group. These results indicate that placebo responses in type I allergy such as allergic rhinitis seem to be induced by cognitive factors such as the patients' expectation as well as mediated by learning processes, with these effects not restricted to a single evocation [129].

Allergic Asthma. Early observations of allergic symptoms in the absence of allergens supported the notion that both patient's expectations and learning mechanisms contribute to the pathophysiology of asthma [123]. Additionally, experimental and clinical data demonstrate that asthma is affected by psychological factors such as stress [130] and can be modulated by interventions other than conventional drug therapy [131]. One example in this context is that viewing a comedy film was able to reduce nonspecific bronchial responsiveness in patients with house dust mite-induced allergic asthma, but not in heathy individuals [111]. A double-blind study in patients with asthma demonstrated that a placebo bronchodilator administration significantly reduced bronchial hyperreactivity (relative to baseline) [132]. In another report, salbutamol was associated with increased forced expiratory volume in $1 \mathrm{~s}$, which was unchanged in the two placebo interventions (placebo inhaler and sham acupuncture) groups. In contrast, the subjective improvement in asthma symptoms reported by the patients in both the inhaled placebo and sham acupuncture groups was significantly greater than the subjective improvement with the no-intervention controls and did not differ compared to the active drug group [133].

$A D$. Patients with $\mathrm{AD}$ often suffer from chronic itch. Orchestrated interactions between histamine-independent $\mathrm{C}$ fibers in the skin, keratinocytes, and immune cells induce pruritus in $\mathrm{AD}$ [78]. The skin is affected by the bidirectional cross-talk among the immune, nervous, and endocrine systems. In response to stress, immune cells in the skin of $\mathrm{AD}$ patients release cytokines, chemokines, and neuropeptides that modulate local inflammatory responses [81]. Additionally, psychological distress and emotional factors are known to play an important role in exacerbating and perpetuating the itch-scratch cycle in $\mathrm{AD}$ [134]. This interaction is documented by a study in which $\mathrm{AD}$ patients receiving histamine reported greater itch when the stimulus was accompanied by negative verbal suggestions about skin response and itch perception [135]. These nocebo-induced itch sensations are associated with the activation of brain regions such as the dorsolateral prefrontal cortex and the striatum in patients with $\mathrm{AD}$ when applying saline while patients expected an allergen [99]. Substantial reductions in itch and severity of skin lesions in the placebo arms of clinical trials suggest that placebo responses are important for clinical practice 
in the therapy of $\mathrm{AD}$ patients $[13,136]$. A recent systematic review and meta-analysis investigated the placebo response in clinical trials evaluating the effect of systemic and biological therapies in adult $\mathrm{AD}$ patients compared with psoriasis patients. In all of the AD studies the daily use of emollients was a requirement and in six studies the use of topical steroids was dictated. At week 12, the pooled proportion of placebo-treated $\mathrm{AD}$ patients that obtained various benchmarks of therapy success was significantly higher than the pooled proportion of placebo-treated psoriasis patients reaching comparable therapy goals [136]. However, placebo rates in clinical trials in general do not allow for dissociating between "true placebo responses" (induced by positive expectation, doctor-patient communication, or prior experience) and natural fluctuations in the underlying disease unless a "no treatment"/"natural history" arm is included $[10,11,15$, 17]. These results emphasize the more fluctuating nature of AD compared to psoriasis. Furthermore, it is conceivable that the expectation of disease reduction when participating in a clinical trial had additional positive effects on $\mathrm{AD}$ in itself [136].

\section{Acute and Chronic Wounds}

In a pilot study it was analyzed whether subjects' expectation of receiving an active medication would accelerate the healing process of experimentally (laser ablation) induced wounds in 22 healthy subjects. In this specific setting, wound healing of acute wounds was not affected by treatment expectation-induced responses [137], which might be due to the small sample size and small wounds in healthy volunteers. In a similar study, healthy participants were provided with information about the beneficial effects of placebos and given a 4-mm punch biopsy wound. Participants were then randomized to either an open-label placebo intervention (two placebo tablets twice a day for 10 days) or a no-treatment control group. Open-label placebo treatment did not improve the healing rate of wounds [138]. In a more recent study in 20 patients with chronic venous leg ulcers, treatment expectation-induced responses did not affect wound healing but significantly improved the wound-related quality of life in these patients [14] (Fig. 1).

\section{Switching from Bio-Originator to Biosimilars}

Biologics have proven their importance in the management of chronic inflammatory and autoimmune diseases. Also in dermatology, biologics are indispensable elements of therapy of various dermatologic conditions, such as psoriasis. Since 2007, the European Medicines
Agency has approved more than 20 biosimilars [139]. During transition from originator to biosimilar therapeutics, patients' expectations have been shown to affect compliance and adherence and to enhance unwanted nocebo effects [22, 140-142]. In the context of extremely expensive therapies and thus limited resources, implementation of an effective health care professional-patient dialogue is key in transferring confidence to the patient and has been shown to reduce nocebo effects when switching from an originator to a biosimilar [139, 143, 144].

\section{Implications for Dermatologic Practice}

The increasing knowledge about treatment expectation effects in skin disorders provides the basis for the systematic exploitation of these effects in order to optimize therapeutic strategies to improve health outcome [ 1 , 11]. However, to date this knowledge has not yet been translated to dermatologic practice and research to improve treatment outcomes in dermatologic patients. Education and training on how to make optimal use of the underlying mechanisms steering patient treatment expectation in clinical practice should be implemented for dermatologists $[6,10,11]$.

\section{Optimizing Expectation Effects}

Health care specialists should be aware that every communication and nonverbal interaction with the patient has the potential to induce either positive or negative expectations, with subsequent effects on physiological responses and treatment efficacy. These effects may happen both consciously and nonconsciously $[10,145]$. The establishment of a trustful patient-clinician relationship paired with a scientifically grounded communication competence is highly essential to make optimal use of treatment expectation effects $[7,21,146]$. Exploration of patient's expectations can be a starting point for routinely incorporating these expectations into clinical practice [7]. Interventions should be administered in a positive context, and positive associations between the therapeutic intervention and contextual factors should be fostered $[7,147]$. It might be helpful to provide positive instructions on how the drug will help the patient and to use rituals and words that focus the patient's attention on the drug and its potential benefits ("There is a large chance that this drug will improve your psoriasis by 90\%”) [21, 147]. Further, patients can profit from talking to other patients or watching videos of other patients who re- 
ceived the same treatment successfully in order to make use of positive social observation $[2,7,10,148]$. In the future, the clinical use of open-label placebos might be reasonable since preliminary data showed encouraging results and ethical concerns can be avoided $[9,85,86]$.

\section{Minimizing Nocebo Effects}

An empathic patient-physician communication builds the basis to help prevent unwanted adverse effects. The communication should be patient-centered when explaining diagnostic procedures, their results, and the rationale and implementation of any intervention [21, 145, 147]. Of course, important side effects must be revealed, but preferably with positive framing [149]. It might be considered mitigating nonserious side effects, e.g., such as skin dryness or irritation under therapy with isotretinoin by mentioning them simply as a minor possibility [150]. It is advisable to convey qualitative information positively instead of negatively by focusing on most patients who do not experience the side effect $[7,151]$. Closely coupling information about adverse events with information about benefits can be a helpful communication strategy [7, 21, 145]. For example, in patients with CSU, it might be helpful to mention potential drowsiness to nonsedating antihistamines while at the same time informing the patient that there is a good chance of symptom improvement. The amount of information and the form of the communication should be tailored to the individual patient [7, 151-153]. A strategy that goes even further is to educate patients about nocebo effects and then to ask them whether they wish to be informed of a benign, nonspecific side effect of a treatment or not $[7,150]$. This approach has been termed "contextualized informed consent" [152] and "authorized concealment" [151]. From a medical point of view, this strategy is promising; however, it might be objected that the approach compromises informed consent because physicians would fail to disclose pertinent risk information to their patients. Thus, prior to clinical use, the theoretical benefits of the concept must be critically weighed against local and national medico-legal (and ethical) constraints. Additionally, reassurance that a side effect may be bothersome but is not harmful or dangerous may relieve the anxiety that is contributing to it [7]. It could even be used for positive framing, e.g., the drug is unfolding its action and serves as a sensory cue to be on a medical treatment $[41,154]$. In clinical routine, it may be helpful to identify patients who are more likely to experience placebo and nocebo effects [150]. However, up to now, no consistent personality profile has emerged so far across various clinical conditions [58]. Future studies are highly needed to further elucidate these features [7].

\section{Implications for Dermatologic Research}

\section{Key Challenges and Open Questions for Basic}

Experimental Research

Knowledge of the mechanisms underlying expectation effects has significantly increased over the last 5 years. However, research into the neurobiology of treatment expectation effects in dermatology is still at a very early stage, and there are several key issues that need to be addressed for future research.

We have to learn which dermatologic conditions are susceptible to respond to placebo and nocebo mechanisms and to what extent these effects are clinically relevant. Further, we have to figure out to which placebo mechanisms various dermatologic symptoms and disorders respond best (e.g., which symptoms are mainly affected by patients' expectations and which diseases are rather responsive to, e.g., conditioning processes?). We also need to discover in how far the mechanisms steering treatment expectation differ on the subjective (e.g., itch and pain) compared to the objective (e.g., intensity of skin lesions) level in various dermatologic diseases. Moreover, the sustainability of patients' treatment expectation effects over several months to years, which is required in the treatment of chronic conditions such as chronic inflammatory dermatoses such as $\mathrm{AD}$ or psoriasis, must be further explored in large samples across various dermatologic diseases.

A major challenge relates to the identification of patient characteristics and psychological predictors that are particularly amenable to placebo or nocebo effects. One of the crucial yet unanswered questions is whether expectation effects and treatment effects (e.g., pharmacologically induced) combine in an additive or interactive manner. This is the fundamental basic assumption behind double-blinded RCTs, hypothesizing that the difference between drug and placebo treatment arms uncovers the "real" drug effect $[3,5]$.

Depending on the drug, its pharmacological mechanisms and expectation that initiates neurobiological cascades may combine in an additive manner for one substance/treatment, but in an interactive fashion for another. Understanding the potential interactions of various levels of expectation and treatment is crucial for two reasons. First, in real-life clinical scenarios, treatments are 
Table 1. Possible approaches for optimizing future trials in allergen immunotherapy (adopted from Pfaar et al. [15])

- Include carefully balanced groups of patients with moderate-to-severe disease with well-defined sensitivity to the target allergen

- Establish prolonged run-in periods prior to treatment allocation

- Apply trial settings that are more typical of where the treatment will subsequently be used

- Consider to use an active allergen placebo in a "double-dummy design" in polysensitized trial participants

- Standardize exposure to aeroallergens by using an allergen exposure chamber

- Use novel, favorable efficacy scales like the peak placebo score weeks

- Consider making use of postmarketing field trial real-world data, but be aware that the data would no longer be acceptable for marketing applications

inalienably associated with a patient's expectation. Thus, in order to tailor the combination of active treatment and expectation optimization strategies to the individual patient, knowledge regarding their combined effect is important. Second, a more comprehensive knowledge of the interaction of pharmacological regimens and treatment expectation has a great impact on the design and interpretation of RCTs. Only the balanced placebo design (full $2 \times 2$ factorial design), which includes both placebo and active treatment, provides the opportunity to delineate the mechanisms and effects of treatment expectation, the treatment itself, and their interaction [155]. Finally, to analyze the success of the transfer of the gained mechanistic knowledge into the clinical context, systematic proof-of-concept studies testing approaches to modulate treatment expectations in patients suffering from various dermatoses must be carefully prepared.

\section{Implications for Clinical Trials}

While in the clinical setting the mechanisms underlying placebo effects should be systematically exploited to maximize treatment benefits, in clinical trials the placebo effect should be minimized in order to be able to assess the actual effects of a specific new treatment, independently of possible placebo and nocebo effects. In this context, approaches to improve "assay sensitivity," the ability of a clinical trial to differentiate between an effective treatment and a less effective or ineffective treatment (e.g., placebo), are highly relevant $[2,3]$. A major challenge of most RCTs is the spontaneous remission and fluctuation of symptoms in many diseases [3]. The problem of disease fluctuation and spontaneous remission applies to many dermatologic conditions, such as $\mathrm{AD}$. Therefore, one approach when designing drug development studies is to include the natural course of conditions without treatment as an additional investigative arm [11]. However, a separate "no-treatment control" group in RCTs is ethically questionable and demo- tivating for patients during recruitment [156]. A recently favored alternative to standard RCTs is the "Zelen design" $[2,157]$. The Zelen design separates the recruitment of patients for an observational study from the recruitment of patients for an intervention study. Provided the sample size for the observational study is large enough and the recruitment of patients for the interventional study does not create a selection bias, the design allows the natural course of the disease to be monitored without randomizing patients to a "no-treatment control” group $[2,157]$. Balanced placebo designs provide the opportunity to dissociate the mechanisms and effects of treatment expectation, the treatment itself, and their interaction [155]. Further approaches that can help control for various components of the placebo effect and to increase "assay sensitivity" in clinical trials are summarized in [2].

Noteworthy, minimizing placebo effects per se does not always improve the "assay sensitivity." Impoverished study designs with very limited placebo mechanisms might also hinder the detection of specific treatment effects and thereby impede drug discovery [2]. Large placebo responses are commonly seen in studies exploring the effect of AIT in allergic conditions which represent a challenge for the approval of new drugs [122]. A recent position paper by the Task Force of the European Academy of Allergy and Clinical Immunology addresses the methodological problem of placebo in AIT and also highlights unmet needs and possible solutions for future trials. Table 1 provides an overview of possible approaches for optimizing future trials in AIT [15]. Most dermatologic trials are not designed by the researchers themselves, but the dermatologic researcher will deal with patients participating in clinical trials. Crucial when working on clinical trials is to assess, control for, homogenize, and possibly minimize expectation across patients and study centers. Training of study nurses and physicians is helpful to standardize and har- 
Table 2. Implications for dermatologic practice and research

\section{Dermatologic practice}

General

- Become familiar with the mechanisms of placebo and nocebo effects and with the fact that every interaction with the patient may induce or modulate expectations [7]

- Educate the medical staff about their responsibility to avoid and reduce nocebo effects and the chances of fostering a positive expectation effect [6]

Promoting placebo effects

- Establish a good patient-clinician relationship and apply an empathic, emotionally warm, authentic interaction style including positive nonverbal behavior $[7,21,146]$

- Explore patients' pretreatment experiences and expectations as part of the medical history [153] and consider the application of standardized assessment tools such as a scale from 0 (no benefit) to 100 (maximum imaginable benefit) [158, 159] or the Treatment Expectation Questionnaire [160]

- Assess whether treatment expectations in an individual patient might be helpful or rather dysfunctional and avoid or correct overly optimistic expectations [5]

- Describe possible effects of the intervention in an adequate and realistic, yet positive way [7]

- Provide positive instructions on how the drug will help the patient and use rituals and words that focus the patient's attention on the drug and its potential benefits ("There is a large chance that this drug will improve your psoriasis by 90\%") [21, 149]

- Consider familiarizing patients with the mechanisms of placebo and nocebo effects as a basis for promoting healing processes [7]

- Consider the use of positive social observation/role models (e.g., video clips with patients expressing some pretreatment concerns but then confirming positive treatment effects) $[2,7,10,148]$

- Support positive associations between the therapeutic intervention and contextual factors and administer interventions in a positive context [7]

- Provide multisensory treatment cues (e.g., visual, olfactory, gustatory) associated with the active medication to promote conditioning processes [30]

- Apply effective pretreatments with low side effects if feasible [161]

Avoiding nocebo effects

- Explore patients' potential negative pretreatment experiences, anxieties, and concerns [7, 150]

- Reveal side effects but preferably with positive framing and couple information about side effects with information about benefits $[7,21,145]$

- Reassure a patient that a side effect may be bothersome, but is not dangerous [7]

- Tailor the amount of information and the form of the communication to the individual patient [152]

- Especially in patients at high risk for nocebo responses, consider mitigating nonserious side effects such as skin dryness by mentioning them simply as a minor possibility $[11,150]$

- Refer to information systems that offer valuable and accurate information [161]

- Minimize negative associations between the therapeutic intervention and contextual factors [7, 150]

- Avoid the use of medical jargon [161]

- Ask proactive check-back questions to prevent negative biases and misunderstandings [7, 161]

- Teach and train the patient strategies to cope with adverse events [161]

\section{Dermatologic research}

Designing randomized controlled trials with higher "assay sensitivity"

- If applicable, include a separate "no-treatment control" group in which the natural course of the disease is followed; consider using the (modified) Zelen design [157]

- Use "balanced placebo" designs to dissociate expectation effects, the treatment itself, and their interaction [155]

- Consider using randomized run-in and withdrawal designs $[2,162,163]$

- Consider using "open-hidden" paradigms in order to separate the effects of the psychosocial context (placebo) from the pharmacodynamic effects of a drug (in the open condition, an active drug is administered by a physician in a visible manner; in the hidden application, the patient receives the same drug dosage, but is unaware of the timing of administration of the medication) $[2,11]$

Dealing with patients participating in a clinical trial

- Assess patients' expectations about the treatment at baseline $[2,7]$

- Stratify patients according to their level of expectation and control for patients' expectations in subgroup analyses [2]

- Standardize and harmonize framing strategies used to present information about the risk-benefit profile of the study and control for center effects [7]

- Use structured checklists to assess adverse events [164]

- Teach and train the study staff about the relevance of a standardized content and style of communication between study team members and the study patient [2]

- Assess what the patient thinks which group he was assigned to at the end of the study [7] 
monize content and style of communication between study team members and the study patient [7]. Ideally, patients should be stratified according to their level of expectation, and subgroup analyses controlled for patients' expectations should be performed. The implications for dermatologic practice and research are summarized in Table 2.

\section{Conclusion}

Placebo and nocebo effects are mediated by cognitive factors, such as patients' expectations, but also by associative learning processes and the quality of doctor-patient communication. The optimization of placebo effects and prevention of unintended nocebo effects can help to ensure that the most efficacious therapeutic outcome is attained. Available data regarding expectation effects in dermatologic conditions are still comparatively scarce. However, the results available strongly indicate that expectation effects have a high impact on dermatologic diseases. The crucial contribution of patients' expectation to the treatment outcomes in dermatology goes along with important implications for the dermatologic practice and demands the implementation of evidence-based recommendations and establishment of training for dermatologists $[6,11]$. Dermatologic researchers need to be informed about strategies to eliminate expectancies and thus be able to best control for possible placebo effects in study designs $[2,11]$. Further characterization of the neurobiological mechanisms underlying placebo and nocebo responses and, importantly, the identification of the predictor variables that influence an individual's placebo and nocebo response in a context and disease-specific manner is necessary to exploit the full potential of these approaches.

Taken together, the emerging knowledge about expectation effects in dermatology provides important opportunities to maximize the therapeutic outcome while minimizing side effects and treatment costs. Future research in this field, thereby also focusing on dermatologic conditions and groups of patients that have not been investigated yet, is highly desired.

\section{Key Message}

Experimental and clinical studies demonstrate that various skin diseases can be modulated by patients' expectations.

\section{Acknowledgment}

We would like to thank Ms. May Schäflein for graphic support and Ms. Delia Cosgrove for proofreading the manuscript.

\section{Conflict of Interest Statement}

Dr. W. Sondermann reports grants from medi GmbH Bayreuth, personal fees from Janssen, grants and personal fees from Novartis, personal fees from Lilly, personal fees from UCB, personal fees from Almirall, personal fees from LEO Pharma, and personal fees from Sanofi Genzyme, outside the submitted work. Dr. F. Reinboldt-Jockenhöfer reports personal fees from Actelion, personal fees from Abbvie, personal fees from Novartis, personal fees from Pierre-Fabre, outside the submitted work. Prof. Dr. J. Dissemond reports personal fees from Abbvie and Celgene, personal fees from Novartis, outside the submitted work. Prof. O. Pfaar reports grants and personal fees from ALK-Abelló, grants and personal fees from Allergopharma, grants and personal fees from Stallergenes Greer, grants and personal fees from HAL Allergy Holding B.V./HAL Allergie $\mathrm{GmbH}$, grants and personal fees from Bencard Allergie $\mathrm{GmbH} /$ Allergy Therapeutics, grants and personal fees from Lofarma, grants from Biomay, grants from Circassia, grants and personal fees from ASIT Biotech Tools S.A., grants and personal fees from Laboratorios LETI/LETI Pharma, personal fees from MEDA Pharma/MYLAN, grants and personal fees from Anergis S.A., personal fees from Mobile Chamber Experts (a GA ${ }^{2} L E N$ Partner), personal fees from Indoor Biotechnologies, grants and personal fees from GlaxoSmithKline, personal fees from Astellas Pharma Global, personal fees from EUFOREA, personal fees from ROXALL Medizin, personal fees from Novartis, personal fees from Sanofi-Aventis and Sanofi-Genzyme, personal fees from med update Europe $\mathrm{GmbH}$, personal fees from streamedup! $\mathrm{GmbH}$, grants from Pohl-Boskamp, grants from Inmunotek S.L., personal fees from John Wiley and Sons, AS, outside the submitted work. Prof. Dr. U. Bingel and Prof. Dr. M. Schedlowski have nothing to disclose.

\section{Funding Sources}

This work was funded by the Deutsche Forschungsgemeinschaft (German Research Foundation), project ID 422744262 TRR 289.

\section{Author Contributions}

W. Sondermann: initial idea, conception and design of the review; drafting of the manuscript; gave final approval of the version to be published. F. Reinboldt-Jockenhöfer, J. Dissemond, O. Pfaar, U. Bingel, and M. Schedlowski: conception and design of the review; drafting and critical revision of the manuscript for important intellectual content; gave final approval of the version to be published. 


\section{References}

1 Colloca L, Miller FG. Harnessing the placebo effect: the need for translational research. Philos Trans R Soc Lond B Biol Sci. 2011 Jun; 366(1572):1922-30.

2 Enck P, Bingel U, Schedlowski M, Rief W. The placebo response in medicine: minimize, maximize or personalize? Nat Rev Drug Discov. 2013 Mar;12(3):191-204.

3 Benedetti F. Placebo effects: from the neurobiological paradigm to translational implications. Neuron. 2014 Nov;84(3):623-37.

4 Kaptchuk TJ, Miller FG. Placebo Effects in Medicine. N Engl J Med. 2015 Jul;373(1):8-9.

5 Schedlowski M, Enck P, Rief W, Bingel U. Neuro-bio-behavioral mechanisms of placebo and nocebo responses: implications for clinical trials and clinical practice. Pharmacol Rev. 2015 Jul;67(3):697-730.

6 Evers AW, Colloca L, Blease C, Annoni M, Atlas LY, Benedetti F, et al. Implications of placebo and nocebo effects for clinical practice: expert consensus. Psychother Psychosom. 2018;87(4):204-10.

7 Colloca L, Barsky AJ. Placebo and nocebo effects. N Engl J Med. 2020 Feb;382(6):554-61.

8 Jütte R. The early history of the placebo. Complement Ther Med. 2013 Apr;21(2):94-7.

9 Petrie KJ, Rief W. Psychobiological mechanisms of placebo and nocebo effects: pathways to improve treatments and reduce side effects. Annu Rev Psychol. 2019 Jan;70(1): 599-625.

10 Benedetti F. Placebo and the new physiology of the doctor-patient relationship. Physiol Rev. 2013 Jul;93(3):1207-46.

11 Evers AW. Using the placebo effect: how expectations and learned immune function can optimize dermatological treatments. Exp Dermatol. 2017 Jan;26(1):18-21.

12 Ader R, Mercurio MG, Walton J, James D, Davis M, Ojha V, et al. Conditioned pharmacotherapeutic effects: a preliminary study. Psychosom Med. 2010 Feb;72(2):192-7.

13 Tekampe J, Peerdeman KJ, Bartels DJ, van Laarhoven AI, Evers AW. Placebo and nocebo effects on itch: methodological and clinical implications. Hautarzt. 2018 Aug;69(8):62630. German.

14 Jockenhöfer F, Knust C, Benson S, Schedlowski M, Dissemond J. Influence of placebo effects on quality of life and wound healing in patients with chronic venous leg ulcers. J Dtsch Dermatol Ges. 2020 Feb;18(2):103-9.

15 Pfaar O, Agache I, Bergmann KC, BindslevJensen C, Bousquet J, Creticos PS, et al. Placebo effects in allergen immunotherapy - an EAACI Task Force Position Paper. Allergy. 2020 doi: 10.1111/all.14331 [Epub ahead of print].

16 Finniss DG, Kaptchuk TJ, Miller F, Benedetti F. Biological, clinical, and ethical advances of placebo effects. Lancet. 2010 Feb;375(9715): 686-95.
17 Colloca L. The placebo effect in pain therapies. Annu Rev Pharmacol Toxicol. 2019 Jan; 59(1):191-211.

18 Bingel U, Wanigasekera $\mathrm{V}$, Wiech $\mathrm{K}, \mathrm{Ni}$ Mhuircheartaigh R, Lee MC, Ploner M, et al. The effect of treatment expectation on drug efficacy: imaging the analgesic benefit of the opioid remifentanil. Sci Transl Med. 2011 Feb;3(70):70ra14

19 Kam-Hansen S, Jakubowski M, Kelley JM, Kirsch I, Hoaglin DC, Kaptchuk TJ, et al. Altered placebo and drug labeling changes the outcome of episodic migraine attacks. Sci Transl Med. 2014 Jan;6(218):218ra5.

20 Rief W, Petrie KJ. Can psychological expectation models be adapted for placebo research? Front Psychol. 2016 Nov; 7:1876.

21 Hansen E, Zech N. Nocebo effects and negative suggestions in daily clinical practice Forms, impact and approaches to avoid them. Front Pharmacol. 2019 Feb;10:77.

22 Kravvariti E, Kitas GD, Mitsikostas DD, Sfikakis PP. Nocebos in rheumatology: emerging concepts and their implications for clinical practice. Nat Rev Rheumatol. 2018 Dec; 14(12):727-40.

23 Colloca L. How do placebo effects and patient-clinician relationships influence behaviors and clinical outcomes? Pain Rep. 2019 Jun;4(3):e758.

24 Bingel U. Placebo 2.0: the impact of expectations on analgesic treatment outcome. Pain. 2020 Sep;161(Suppl 1):S48-56.

25 Egbert LD, Battit GE, Welch CE, Bartlett MK. Reduction of postoperative pain by encouragement and instruction of patients. A study of doctor-patient rapport. N Engl J Med. 1964 Apr;270(16):825-7.

26 Mondaini N, Gontero P, Giubilei G, Lombardi G, Cai T, Gavazzi A, et al. Finasteride $5 \mathrm{mg}$ and sexual side effects: how many of these are related to a nocebo phenomenon? J Sex Med. 2007 Nov; 4(6): 1708-12.

27 Rief W, Nestoriuc Y, von Lilienfeld-Toal A, Dogan I, Schreiber F, Hofmann SG, et al. Differences in adverse effect reporting in placebo groups in SSRI and tricyclic antidepressant trials: a systematic review and meta-analysis. Drug Saf. 2009;32(11):1041-56.

28 Czerniak E, Biegon A, Ziv A, Karnieli-Miller $\mathrm{O}$, Weiser M, Alon U, et al. Manipulating the placebo response in experimental pain by altering doctor's performance style. Front Psychol. 2016 Jun;7:874.

29 Colloca L, Sigaudo M, Benedetti F. The role of learning in nocebo and placebo effects. Pain. 2008 May; 136(1-2):211-8.

30 Doering BK, Rief W. Utilizing placebo mechanisms for dose reduction in pharmacotherapy. Trends Pharmacol Sci. 2012 Mar;33(3): 165-72.

31 Goebel MU, Trebst AE, Steiner J, Xie YF, Exton MS, Frede S, et al. Behavioral conditioning of immunosuppression is possible in humans. FASEB J. 2002 Dec;16(14):1869-73.
32 Goebel MU, Meykadeh N, Kou W, Schedlowski M, Hengge UR. Behavioral conditioning of antihistamine effects in patients with allergic rhinitis. Psychother Psychosom. 2008;77(4):227-34.

33 Albring A, Wendt L, Benson S, Nissen S, Yavuz Z, Engler H, et al. Preserving learned immunosuppressive placebo response: perspectives for clinical application. Clin Pharmacol Ther. 2014 Aug;96(2):247-55.

34 Kirchhof J, Petrakova L, Brinkhoff A, Benson $S$, Schmidt J, Unteroberdörster $M$, et al. Learned immunosuppressive placebo responses in renal transplant patients. Proc Natl Acad Sci USA. 2018 Apr;115(16):4223-7.

35 Hadamitzky M, Lückemann L, PachecoLópez G, Schedlowski M. Pavlovian conditioning of immunological and neuroendocrine functions. Physiol Rev. 2020 Jan;100(1): 357-405.

36 Colloca L, Benedetti F. Placebo analgesia induced by social observational learning. Pain. 2009 Jul;144(1-2):28-34.

37 Zhang H, Zhou L, Wei H, Lu X, Hu L. The sustained influence of prior experience induced by social observation on placebo and nocebo responses. J Pain Res. 2017 Dec;10: 2769-80.

38 Koban L, Jepma M, López-Solà M, Wager TD Different brain networks mediate the effects of social and conditioned expectations on pain. Nat Commun. 2019 Sep;10(1):4096.

39 Ulrich RS. View through a window may influence recovery from surgery. Science. 1984 Apr;224(4647):420-1.

40 Meissner K, Linde K. Are blue pills better than green? How treatment features modulate placebo effects. Int Rev Neurobiol. 2018;139: 357-78.

41 Rief W, Glombiewski JA. The hidden effects of blinded, placebo-controlled randomized trials: an experimental investigation. Pain. 2012 Dec;153(12):2473-7.

42 Meissner K, Fässler M, Rücker G, Kleijnen J, Hróbjartsson A, Schneider A, et al. Differential effectiveness of placebo treatments: a systematic review of migraine prophylaxis. JAMA Intern Med. 2013 Nov;173(21):194151.

43 Peciña M, Zubieta JK. Molecular mechanisms of placebo responses in humans. Mol Psychiatry. 2015 Apr;20(4):416-23.

44 Wager TD, Atlas LY. The neuroscience of placebo effects: connecting context, learning and health. Nat Rev Neurosci. 2015 Jul;16(7):40318.

45 Zunhammer M, Bingel U, Wager TD; Placebo Imaging Consortium. Placebo effects on the neurologic pain signature: A meta-analysis of individual participant functional magnetic resonance imaging data. JAMA Neurol. 2018 Nov;75(11):1321-30 
46 Krummenacher P, Candia V, Folkers G, Schedlowski M, Schönbächler G. Prefrontal cortex modulates placebo analgesia. Pain. 2010 Mar;148(3):368-74.

47 Benedetti F, Arduino C, Costa S, Vighetti S, Tarenzi L, Rainero I, et al. Loss of expectationrelated mechanisms in Alzheimer's disease makes analgesic therapies less effective. Pain. 2006 Mar;121(1-2):133-44.

48 Zubieta JK, Bueller JA, Jackson LR, Scott DJ, Xu Y, Koeppe RA, et al. Placebo effects mediated by endogenous opioid activity on $\mathrm{mu}$ opioid receptors. J Neurosci. 2005 Aug; 25(34):7754-62.

49 Kong J, Gollub RL, Rosman IS, Webb JM, Vangel MG, Kirsch I, et al. Brain activity associated with expectancy-enhanced placebo analgesia as measured by functional magnetic resonance imaging. J Neurosci. 2006 Jan; 26(2):381-8.

50 Jensen $\mathrm{KB}$. What is minimally required to elicit placebo effects? Int Rev Neurobiol. 2018; 138:181-99.

51 Benedetti F, Pollo A, Colloca L. Opioid-mediated placebo responses boost pain endurance and physical performance: is it doping in sport competitions? J Neurosci. 2007 Oct; 27(44):11934-9.

52 Eippert F, Bingel U, Schoell ED, Yacubian J, Klinger R, Lorenz J, et al. Activation of the opioidergic descending pain control system underlies placebo analgesia. Neuron. 2009 Aug;63(4):533-43.

53 Benedetti F, Amanzio M, Rosato R, Blanchard C. Nonopioid placebo analgesia is mediated by CB1 cannabinoid receptors. Nat Med. 2011 Oct;17(10):1228-30.

54 Skyt I, Lunde SJ, Baastrup C, Svensson P, Jensen TS, Vase L. Neurotransmitter systems involved in placebo and nocebo effects in healthy participants and patients with chronic pain: a systematic review. Pain. 2020 Jan; 161(1):11-23.

55 Benedetti F, Amanzio M, Vighetti S, Asteggiano $\mathrm{G}$. The biochemical and neuroendocrine bases of the hyperalgesic nocebo effect. J Neurosci. 2006 Nov;26(46):12014-22.

56 Pacheco-López G, Niemi MB, Kou W, Härting M, Fandrey J, Schedlowski M. Neural substrates for behaviorally conditioned immunosuppression in the rat. J Neurosci. 2005 Mar;25(9):2330-7.

57 Kaptchuk TJ, Kelley JM, Deykin A, Wayne PM, Lasagna LC, Epstein IO, et al. Do "placebo responders" exist? Contemp Clin Trials. 2008 Jul;29(4):587-95.

58 Horing B, Weimer K, Muth ER, Enck P. Prediction of placebo responses: a systematic review of the literature. Front Psychol. 2014 Oct; $5: 1079$.

59 Benedetti F, Frisaldi E. Creating placebo responders and nonresponders in the laboratory: boons and banes. Pain Manag. 2014 May;4(3):165-7.

60 Hall KT, Loscalzo J, Kaptchuk TJ. Genetics and the placebo effect: the placebome. Trends Mol Med. 2015 May;21(5):285-94.
61 Colloca L, Benedetti F. Nocebo hyperalgesia: how anxiety is turned into pain. Curr Opin Anaesthesiol. 2007 Oct;20(5):435-9.

62 Lyby PS, Aslaksen PM, Flaten MA. Is fear of pain related to placebo analgesia? J Psychosom Res. 2010 Apr;68(4):369-77.

63 Lyby PS, Aslaksen PM, Flaten MA. Variability in placebo analgesia and the role of fear of pain - an ERP study. Pain. 2011 Oct;152(10): 2405-12.

64 Lyby PS, Forsberg JT, Asli O, Flaten MA. Induced fear reduces the effectiveness of a placebo intervention on pain. Pain. 2012 May; 153(5):1114-21.

65 Kong J, Spaeth R, Cook A, Kirsch I, Claggett $B$, Vangel M, et al. Are all placebo effects equal? Placebo pills, sham acupuncture, cue conditioning and their association. PLoS One. 2013 Jul;8(7):e67485.

66 Lund K, Petersen GL, Erlandsen M, De Pascalis V, Vase L, Jensen TS, et al. The magnitude of placebo analgesia effects depends on how they are conceptualized. J Psychosom Res. 2015 Dec;79(6):663-8.

67 Schmid J, Langhorst J, Gaß F, Theysohn N, Benson S, Engler H, et al. Placebo analgesia in patients with functional and organic abdominal pain: a fMRI study in IBS, UC and healthy volunteers. Gut. 2015 Mar;64(3):418-27.

68 Vase L, Riley JL 3rd, Price DD. A comparison of placebo effects in clinical analgesic trials versus studies of placebo analgesia. Pain. 2002 Oct;99(3):443-52.

69 Kaptchuk TJ, Hemond CC, Miller FG. Placebos in chronic pain: evidence, theory, ethics, and use in clinical practice. BMJ. $2020 \mathrm{Jul}$; 370:m1668.

70 Baliki MN, Petre B, Torbey S, Herrmann KM, Huang L, Schnitzer TJ, et al. Corticostriatal functional connectivity predicts transition to chronic back pain. Nat Neurosci. 2012 Jul; 15(8):1117-9.

71 Hashmi JA, Baria AT, Baliki MN, Huang L, Schnitzer TJ, Apkarian AV. Brain networks predicting placebo analgesia in a clinical trial for chronic back pain. Pain. 2012 Dec;153(12): 2393-402.

72 Hashmi JA, Kong J, Spaeth R, Khan S, Kaptchuk TJ, Gollub RL. Functional network architecture predicts psychologically mediated analgesia related to treatment in chronic knee pain patients. J Neurosci. 2014 Mar; 34(11):3924-36.

73 Kucyi A, Moayedi M, Weissman-Fogel I, Goldberg MB, Freeman BV, Tenenbaum HC, et al. Enhanced medial prefrontal-default mode network functional connectivity in chronic pain and its association with pain rumination. J Neurosci. 2014 Mar;34(11):396975.

74 Schmidt-Wilcke T, Ichesco E, Hampson JP, Kairys A, Peltier S, Harte S, et al. Resting state connectivity correlates with drug and placebo response in fibromyalgia patients. Neuroimage Clin. 2014 Sep;6:252-61.
75 Tétreault P, Mansour A, Vachon-Presseau E, Schnitzer TJ, Apkarian AV, Baliki MN. Brain connectivity predicts placebo response across chronic pain clinical trials. PLoS Biol. 2016 Oct;14(10):e1002570.

76 Bosma RL, Cheng JC, Rogachov A, Kim JA, Hemington KS, Osborne NR, et al. Brain dynamics and temporal summation of pain predicts neuropathic pain relief from ketamine infusion. Anesthesiology. 2018 Nov;129(5): 1015-24.

77 Colagiuri B, Schenk LA, Kessler MD, Dorsey SG, Colloca L. The placebo effect: from concepts to genes. Neuroscience. 2015 Oct;307: $171-90$.

78 Yosipovitch G, Soung J, Weiss J, Muscianisi E, Meng X, Gilloteau I, et al. Secukinumab provides rapid relief from itching and pain in patients with moderate-to-severe psoriasis: patient symptom diary data from two phase 3 , randomized, placebo-controlled clinical trials. Acta Derm Venereol. 2019 Jul;99(9):8201.

79 Silverberg JI, Hinami K, Trick WE, Cella D. Itch in the general internal medicine setting: A cross-sectional study of prevalence and quality-of-life effects. Am J Clin Dermatol. 2016 Dec;17(6):681-90.

80 Steinke S, Zeidler C, Riepe C, Bruland P, SotoRey I, Storck M, et al. Humanistic burden of chronic pruritus in patients with inflammatory dermatoses: Results of the European Academy of Dermatology and Venereology Network on Assessment of Severity and Burden of Pruritus (PruNet) cross-sectional trial. J Am Acad Dermatol. 2018 Sep;79(3):457463.e5.

81 Suárez AL, Feramisco JD, Koo J, Steinhoff M. Psychoneuroimmunology of psychological stress and atopic dermatitis: pathophysiologic and therapeutic updates. Acta Derm Venereol. 2012 Jan;92(1):7-15.

82 Meeuwis SH, van Middendorp H, van Laarhoven AI, van Leijenhorst C, Pacheco-Lopez G, Lavrijsen AP, et al. Placebo and nocebo effects for itch and itch-related immune outcomes: A systematic review of animal and human studies. Neurosci Biobehav Rev. 2020 Jun;113:325-37.

83 van Laarhoven AI, Vogelaar ML, WilderSmith OH, van Riel PL, van de Kerkhof PC, Kraaimaat FW, et al. Induction of nocebo and placebo effects on itch and pain by verbal suggestions. Pain. 2011 Jul;152(7):1486-94

84 Bartels DJ, van Laarhoven AI, Haverkamp EA, Wilder-Smith $\mathrm{OH}$, Donders AR, van Middendorp H, et al. Role of conditioning and verbal suggestion in placebo and nocebo effects on itch. PLoS One. 2014 Mar; 9(3):e91727.

85 Colloca L, Howick J. Placebos Without deception: outcomes, mechanisms, and ethics. Int Rev Neurobiol. 2018;138:219-40.

86 Kaptchuk TJ. Open-Label placebo: reflections on a research agenda. Perspect Biol Med. 2018;61(3):311-34 
87 Meeuwis SH, van Middendorp H, Veldhuijzen DS, van Laarhoven AI, De Houwer J, Lavrijsen AP, et al. Placebo effects of openlabel verbal suggestions on itch. Acta Derm Venereol. 2018 Feb;98(2):268-74.

88 Meeuwis SH, van Middendorp H, van Laarhoven AI, Veldhuijzen DS, Lavrijsen AP, Evers AW. Effects of open- and closed-label nocebo and placebo suggestions on itch and itch expectations. Front Psychiatry. 2019 Jun; 10:436.

89 Sandler AD, Bodfish JW. Open-label use of placebos in the treatment of ADHD: a pilot study. Child Care Health Dev. 2008 Jan;34(1): 104-10.

90 Kaptchuk TJ, Friedlander E, Kelley JM, Sanchez MN, Kokkotou E, Singer JP, et al. Placebos without deception: a randomized controlled trial in irritable bowel syndrome. PLoS One. 2010 Dec;5(12):e15591.

91 Kelley JM, Kaptchuk TJ, Cusin C, Lipkin S, Fava M. Open-label placebo for major depressive disorder: a pilot randomized controlled trial. Psychother Psychosom. 2012;81(5): $312-4$.

92 Carvalho C, Caetano JM, Cunha L, Rebouta P, Kaptchuk TJ, Kirsch I. Open-label placebo treatment in chronic low back pain: a randomized controlled trial. Pain. 2016 Dec; 157(12):2766-72.

93 Charlesworth JE, Petkovic G, Kelley JM, Hunter M, Onakpoya I, Roberts N, et al. Effects of placebos without deception compared with no treatment: A systematic review and meta-analysis. J Evid Based Med. 2017 May; 10(2):97-107.

94 Hoenemeyer TW, Kaptchuk TJ, Mehta TS, Fontaine KR. Open-label placebo treatment for cancer-related fatigue: A randomizedcontrolled clinical trial. Sci Rep. 2018 Feb; $8(1): 2784$

95 Kleine-Borgmann J, Schmidt K, Hellmann A, Bingel U. Effects of open-label placebo on pain, functional disability, and spine mobility in patients with chronic back pain: a randomized controlled trial. Pain. 2019 Dec;160(12): 2891-7.

96 Meeuwis SH, van Middendorp H, PachecoLopez G, Ninaber MK, Lavrijsen AP, van der Wee N, et al. Antipruritic placebo effects by conditioning $\mathrm{H} 1$-antihistamine. Psychosom Med. 2019 Nov/Dec;81(9):841-50.

97 Holle H, Warne K, Seth AK, Critchley HD, Ward J. Neural basis of contagious itch and why some people are more prone to it. Proc Natl Acad Sci USA. 2012 Nov;109(48):1981621.

98 Schut C, Mochizuki H, Grossman SK, Lin AC, Conklin CJ, Mohamed FB, et al. Brain processing of contagious itch in patients with atopic dermatitis. Front Psychol. 2017 Jul;8: 1267.

99 Napadow V, Li A, Loggia ML, Kim J, Mawla I, Desbordes G, et al. The imagined itch: brain circuitry supporting nocebo-induced itch in atopic dermatitis patients. Allergy. $2015 \mathrm{Nov}$; 70(11):1485-92.
100 van de Sand MF, Menz MM, Sprenger C, Büchel C. Nocebo-induced modulation of cerebral itch processing - An fMRI study. Neuroimage. 2018 Feb;166:209-18.

101 Grob JJ, Revuz J, Ortonne JP, Auquier P, Lorette G. Comparative study of the impact of chronic urticaria, psoriasis and atopic dermatitis on the quality of life. Br J Dermatol. 2005 Feb;152(2):289-95.

102 Pasaoglu G, Bavbek S, Tugcu H, Abadoglu $\mathrm{O}$, Misirligil Z. Psychological status of patients with chronic urticaria. J Dermatol. 2006 Nov;33(11):765-71.

103 Rubini NP, Ensina LF, Silva EM, Sano F, Solé D. Effectiveness and safety of Omalizumab in the treatment of chronic spontaneous urticaria: systematic review and meta-analysis. Allergol Immunopathol (Madr). 2019 Nov-Dec;47(6):515-22.

104 van Laarhoven AI, van der Sman-Mauriks IM, Donders AR, Pronk MC, van de Kerkhof PC, Evers AW. Placebo effects on itch: a meta-analysis of clinical trials of patients with dermatological conditions. J Invest Dermatol. 2015 May;135(5):1234-43.

105 Zhao ZT, Ji CM, Yu WJ, Meng L, Hawro T, Wei JF, et al. Omalizumab for the treatment of chronic spontaneous urticaria: a metaanalysis of randomized clinical trials. J Allergy Clin Immunol. 2016 Jun;137(6):17421750.e4.

106 Maurer M, Giménez-Arnau AM, Sussman G, Metz M, Baker DR, Bauer A, et al. Ligelizumab for chronic spontaneous urticaria. N Engl J Med. 2019 Oct;381(14):1321-32.

107 Rapp SR, Feldman SR, Exum ML, Fleischer $\mathrm{AB}$ Jr, Reboussin DM. Psoriasis causes as much disability as other major medical diseases. J Am Acad Dermatol. 1999 Sep;41(3 Pt 1):401-7.

108 Koo J, Marangell LB, Nakamura M, Armstrong A, Jeon C, Bhutani T, et al. Depression and suicidality in psoriasis: review of the literature including the cytokine theory of depression. J Eur Acad Dermatol Venereol. 2017 Dec;31(12):1999-2009.

109 Ayasse MT, Buddenkotte J, Alam M, Steinhoff $\mathrm{M}$. Role of neuroimmune circuits and pruritus in psoriasis. Exp Dermatol. 2020 Apr;29(4):414-26.

110 Kimata H. Listening to Mozart reduces allergic skin wheal responses and in vitro allergen-specific IgE production in atopic dermatitis patients with latex allergy. Behav Med. 2003;29(1):15-9.

111 Kimata H. Effect of viewing a humorous vs. nonhumorous film on bronchial responsiveness in patients with bronchial asthma. Physiol Behav. 2004 Jun;81(4):681-4.

112 Beecher HK. The powerful placebo. J Am Med Assoc. 1955 Dec;159(17):1602-6.

113 Hróbjartsson A, Gøtzsche PC. Is the placebo powerless? An analysis of clinical trials comparing placebo with no treatment. $\mathrm{N}$ Engl J Med. 2001 May;344(21):1594-602.
114 Eccles R. The power of the placebo. Curr Allergy Asthma Rep. 2007 May;7(2):100-4.

115 Hrobjartsson A, Gotzsche PC. Placebo interventions for all clinical conditions. Cochrane Database Syst Rev. 2010 Jan; 2010(1):CD003974.

116 del Cuvillo A, Sastre J, Bartra J, Mullol J, DáVila I, Montoro J, et al. Placebo effect in clinical trials involving patients with allergic rhinitis. J Investig Allergol Clin Immunol. 2011;21(Suppl 3):40-5

117 Frew AJ, Pfaar O. Placebo effects in allergen immunotherapy: an experts' opinion. Allergo J Int. 2018;27(6):162-6.

118 Kiecolt-Glaser JK, Heffner KL, Glaser R, Malarkey WB, Porter K, Atkinson C, et al. How stress and anxiety can alter immediate and late phase skin test responses in allergic rhinitis. Psychoneuroendocrinology. 2009 Jun;34(5):670-80.

119 Wedi B, Wieczorek D, Kapp A. Placebo effect in clinical trials with allergen-specific immunotherapy with inhalant allergens. Hautarzt. 2017 Apr;68(4):297-306. German.

120 Kimata H. Kissing reduces allergic skin wheal responses and plasma neurotrophin levels. Physiol Behav. 2003 Nov;80(2-3): 395-8.

121 Langewitz W, Izakovic J, Wyler J, Schindler C, Kiss A, Bircher AJ. Effect of self-hypnosis on hay fever symptoms - a randomised controlled intervention study. Psychother Psychosom. 2005;74(3):165-72.

122 Narkus A, Lehnigk U, Haefner D, Klinger R, Pfaar O, Worm M. The placebo effect in allergen-specific immunotherapy trials. Clin Transl Allergy. 2013 Dec;3(1):42.

123 Turnbull JW. Asthma conceived as a learned response. J Psychosom Res. 1962 Jan-Mar; 6(1):59-70.

124 Pfaar O, Agache I, de Blay F, Bonini S, Chaker AM, Durham SR, et al. Perspectives in allergen immunotherapy: 2019 and beyond. Allergy. 2019 Dec;74(Suppl 108):3-25.

125 Schaefer M, Harke R, Denke C. Open-label placebos improve symptoms in allergic rhinitis: a randomized controlled trial. Psychother Psychosom. 2016;85(6):373-4.

126 Schaefer M, Sahin T, Berstecher B. Why do open-label placebos work? A randomized controlled trial of an open-label placebo induction with and without extended information about the placebo effect in allergic rhinitis. PLoS One. 2018 Mar; 13(3): 0192758.

127 Gauci M, Husband AJ, Saxarra H, King MG Pavlovian conditioning of nasal tryptase release in human subjects with allergic rhinitis. Physiol Behav. 1994 May;55(5):823-5.

128 Barrett JE, King MG, Pang G. Conditioning rhinitis in allergic humans. Ann N Y Acad Sci. 2000;917(1):853-9.

129 Vits S, Cesko E, Benson S, Rueckert A, Hillen $U$, Schadendorf $D$, et al. Cognitive factors mediate placebo responses in patients with house dust mite allergy. PLoS One. 2013 Nov;8(11):e79576. 
130 Bienenstock J. Stress and asthma: the plot thickens. Am J Respir Crit Care Med. 2002 Apr;165(8):1034-5.

131 Nickel C, Lahmann C, Muehlbacher M, Pedrosa Gil F, Kaplan P, Buschmann W, et al. Pregnant women with bronchial asthma benefit from progressive muscle relaxation: a randomized, prospective, controlled trial. Psychother Psychosom. 2006;75(4):237-43.

132 Kemeny ME, Rosenwasser LJ, Panettieri RA, Rose RM, Berg-Smith SM, Kline JN. Placebo response in asthma: a robust and objective phenomenon. J Allergy Clin Immunol. 2007 Jun;119(6):1375-81.

133 Wechsler ME, Kelley JM, Boyd IO, Dutile S, Marigowda G, Kirsch I, et al. Active albuterol or placebo, sham acupuncture, or no intervention in asthma. N Engl J Med. 2011 Jul;365(2):119-26.

134 Maksimovic N, Zaric M, Bjelica S, Eric Marinkovic J, Jankovic S. Psychosomatic factors of atopic dermatitis exacerbation. Int J Dermatol. 2018 Sep;57(9):1080-4.

135 Scholz O, Hermanns N. Illness behavior and cognitions influence the perception of itching of patients suffering from atopic dermatitis. Z Klin Psychol. 1994;23:127-35.

136 Andreasen TH, Christensen MO, Halling AS, Egeberg A, Thyssen JP. Placebo response in phase 2 and 3 trials of systemic and biological therapies for atopic dermatitis - a systematic review and meta-analysis. J Eur Acad Dermatol Venereol. 2020 Jun; 34(6):1143-50.

137 Vits S, Dissemond J, Schadendorf D, Kriegler L, Körber A, Schedlowski M, et al. Expectation-induced placebo responses fail to accelerate wound healing in healthy volunteers: results from a prospective controlled experimental trial. Int Wound J. 2015 Dec;12(6):664-8.

138 Mathur A, Jarrett P, Broadbent E, Petrie KJ. Open-label placebos for wound healing: A randomized controlled trial. Ann Behav Med. 2018 Sep;52(10):902-8.

139 Rezk MF, Pieper B. To See or NOsee: the debate on the nocebo effect and optimizing the use of biosimilars. Adv Ther. 2018 Jun; 35(6):749-53.

140 Rezk MF, Pieper B. Treatment outcomes with biosimilars: be aware of the nocebo effect. Rheumatol Ther. 2017 Dec;4(2):209-18.

141 Tweehuysen L, Huiskes VI, van den Bemt BJ, Vriezekolk JE, Teerenstra $S$, van den Hoogen FH, et al. Open-label, non-manda- tory transitioning from originator etanercept to biosimilar SB4: six-month results from a controlled cohort study. Arthritis Rheumatol. 2018 Sep;70(9):1408-18.

142 Bakalos G, Zintzaras E. Drug discontinuation in studies including a switch from an originator to a biosimilar monoclonal antibody: A systematic literature review. Clin Ther. 2019 Jan;41(1):155-173.e13.

143 Pouillon L, Socha M, Demore B, Thilly N, Abitbol V, Danese S, et al. The nocebo effect: a clinical challenge in the era of biosimilars. Expert Rev Clin Immunol. 2018 Sep;14(9): 739-49.

144 Pouillon L, Danese S, Hart A, Fiorino G, Argollo M, Selmi C, et al. Consensus report: clinical recommendations for the prevention and management of the nocebo effect in biosimilar-treated IBD patients. Aliment Pharmacol Ther. 2019 May;49(9):1181-7.

145 Barsky AJ. The Iatrogenic Potential of the Physician's Words. JAMA. 2017 Dec; 318(24):2425-6.

146 Barsky AJ, Saintfort R, Rogers MP, Borus JF. Nonspecific medication side effects and the nocebo phenomenon. JAMA. 2002 Feb; 287(5):622-7.

147 Colloca L, Finniss D. Nocebo effects, patient-clinician communication, and therapeutic outcomes. JAMA. 2012 Feb;307(6): 567-8.

148 Colloca L, Miller FG. How placebo responses are formed: a learning perspective. Philos Trans R Soc Lond B Biol Sci. 2011 Jun; 366(1572):1859-69.

149 Barnes K, Faasse K, Geers AL, Helfer SG, Sharpe L, Colloca L, et al. Can positive framing reduce nocebo side effects? Current evidence and recommendation for future research. Front Pharmacol. 2019 Mar; 10:167.

150 Sonthalia S, Sahaya K, Arora R, Singal A, Srivastava A, Wadhawan R, et al. Nocebo effect in Dermatology. Indian J Dermatol Venereol Leprol. 2015 May-Jun;81(3):242-50.

151 Colloca L, Miller FG. The nocebo effect and its relevance for clinical practice. Psychosom Med. 2011 Sep;73(7):598-603.

152 Wells RE, Kaptchuk TJ. To tell the truth, the whole truth, may do patients harm: the problem of the nocebo effect for informed consent. Am J Bioeth. 2012;12(3):22-9.

153 Colloca L. Nocebo effects can make you feel pain. Science. 2017 Oct;358(6359):44.

154 Berna C, Kirsch I, Zion SR, Lee YC, Jensen KB, Sadler P, et al. Side effects can enhance treatment response through expectancy effects: an experimental analgesic randomized controlled trial. Pain. 2017 Jun;158(6): 1014-20.

155 Rohsenow DJ, Marlatt GA. The balanced placebo design: methodological considerations. Addict Behav. 1981;6(2):107-22.

156 Tedeschini E, Fava M, Goodness TM, Papakostas GI. Relationship between probability of receiving placebo and probability of prematurely discontinuing treatment in double-blind, randomized clinical trials for MDD: a meta-analysis. Eur Neuropsychopharmacol. 2010 Aug;20(8):562-7.

157 Zelen M. A new design for randomized clinical trials. N Engl J Med. 1979 May;300(22): 1242-5.

158 Vase L, Robinson ME, Verne GN, Price DD The contributions of suggestion, desire, and expectation to placebo effects in irritable bowel syndrome patients. An empirical investigation. Pain. 2003 Sep;105(1-2):17-25.

159 Benedetti F, Carlino E, Piedimonte A. Increasing uncertainty in CNS clinical trials: the role of placebo, nocebo, and Hawthorne effects. Lancet Neurol. 2016 Jun;15(7):73647.

160 Shedden-Mora M, Alberts J, Petrie K, Laferton J, Nestoriuc Y, Löwe B. The Treatment Expectation Questionnaire (TEX-Q) - A generic multidimensional scale measuring patients' treatment expectations. J Psychosom Res. 2019;121:129-30.

161 Bingel U; Placebo Competence Team. Avoiding nocebo effects to optimize treatment outcome. JAMA. 2014 Aug;312(7): 693-4.

162 Mallinckrodt C, Chuang-Stein C, McSorley P, Schwartz J, Archibald DG, Perahia DG, et al. A case study comparing a randomized withdrawal trial and a double-blind longterm trial for assessing the long-term efficacy of an antidepressant. Pharm Stat. 2007 Jan-Mar;6(1):9-22.

163 Ivanova A, Tamura RN. A two-way enriched clinical trial design: combining advantages of placebo lead-in and randomized withdrawal. Stat Methods Med Res. 2015 Dec;24(6):871-90.

164 Rief W, Barsky AJ, Glombiewski JA, Nestoriuc $\mathrm{Y}$, Glaesmer $\mathrm{H}$, Braehler E. Assessing general side effects in clinical trials: reference data from the general population. Pharmacoepidemiol Drug Saf. 2011 Apr; 20(4):405-15. 